\title{
Fechner as a pioneering theorist of unconscious cognition
}

\author{
David Romand
}

SPHERE (Science, Philosophy, History)

UMR 7219 - CNRS / Université Paris-Diderot-Paris 7

Bâtiment Condorcet - Case 7093

5 , rue Thomas Mann

75205 Paris Cedex 3 - France

Email: david_romand@hotmail.fr

Published in: Consciousness and Cognition, 21, 2012, 562-572. 


\begin{abstract}
Fechner remains virtually unknown for his psychological research on the unconscious. However, he was one of the most prominent theorists of unconscious cognition of the 19th century, in the context of the rise of scientific investigations on the unconscious in German psychology. In line with the models previously developed by Leibniz and Herbart, Fechner proposes an explanative system of unconscious phenomena based on a modular conception of the mind and on the idea of a functional dissociation between representational and attentional activity. For Fechner, the unconscious is a state of consciousness resulting from the isolation of representational activity from the rest of psychical life. Unconscious mental phenomena are unattended mental states that behave autonomously while remaining able to act on consciousness. This paper aims to revisit Fechner's contribution to the history of the unconscious, but also the theoretical significance of the Fechnerian unconscious vis-à-vis current research on the cognitive unconscious.
\end{abstract}

\title{
Keywords
}

Gustav Theodor Fechner; unconscious cognition; cognitive unconscious; consciousness; representation; attention; German psychology; psychophysics. 


\section{Introduction}

Gustav Theodor Fechner (1801-1887) is nowadays almost exclusively regarded as the founder of the psychophysical method and more generally speaking as one of the pioneers of experimental psychology (Boring, 1950; Brožek \& Gundlach, 1988) - two domains to the creation of which he effectively contributed in his major work, the Elemente der Psychophysik ("Elements of psychophysics"), first published in 1860 (Fechner, 1860a/1966, $1860 \mathrm{~b})$. Such a view is in reality very reductive, since Fechner was also, and perhaps above all, one of the greatest theorists of psychology and one of the most prominent philosophers of mind of the $19^{\text {th }}$ century. This bias in the reception of the Fechnerian thought is perfectly exemplified by the semantic change of the term "psychophysics", which currently refers to the quantitative and formal study of the effects of stimuli on sensory data, but which, in Fechner's primitive conception, referred to a global model of cognition (of which the "psychophysics" in its modern acceptation is only one particular aspect). Among the many psychological topics discussed by Fechner, the unconscious is clearly one of the most tantalizing, but also one of those that have been most neglected by the commentators. The issue of the unconscious is developed in detail, together with the issue of consciousness, in the second part of the Elemente, which is dedicated to the so-called "internal psychophysics", i.e., the investigation of the immediate relations of correspondence between the psychical and the physical (i.e. qualitative and quantitative relationships between mental states and brain activity), by contrast with the first part of the book, which is dedicated to "external psychophysics", the investigation of the mediate relations of correspondence between the psychical and the physical (i.e. relationships between sensations and stimuli) (Fechner, 1860b, but see also, Fechner, 1851, 1877, 1879). It is worth noting that the second part of the Elemente, by far the most interesting from the theoretically point of view, has never been 
translated into English, and that it seems to have been relatively of modest influence during the $19^{\text {th }}$ century. In any case, one is forced to admit that Fechner's theory of the unconscious has been only briefly and superficially commented by historians of psychology (Brožek \& Gundach, 1988; Heidelberger, 1993/2004, 2010; Sachs-Hombach, 1993; Arendt, 1999; Fix \& Altmann, 2003). According to the classically accepted interpretation (Heidelberger, 2010), the Fechnerian unconscious would be largely answerable to a metaphysical and pseudoscientific worldview inherited from Fechner's youthful interest for romantic philosophy and Naturphilosophie.

In the present paper, I challenge this assumption and consider on the contrary that the Fechnerian conception of the unconscious is in reality inseparable from his project of a scientific psychology and from his rationalistic approach of psychological phenomena. According to me, Fechner's unconscious should be basically understood within the theoretical and epistemological framework of his psychophysical system, and more generally speaking in the context of the new psychological paradigm that emerges in German-speaking countries during the $19^{\text {th }}$ century - a scientific conception of the mind that, as I showed elsewhere, consists in fact in the manifestation of a cognitive program of research (Romand \& Tchougounnikov, 2009; Romand, 2010). In this respect, I maintain that the theory of the unconscious proposed by Fechner should be interpreted as being an early model of cognitive unconscious or unconscious cognition, in the sense these two synonymous expressions have in modern psychology and neuroscience (Kihlstrom, 1987, 2002; Schacter, 1992; Ederlyi, 2004; Cleeremans, 2006; Dehaene et al., 2006; Augusto, 2010). I will show that Fechner, like the other German psychologists of the $19^{\text {th }}$ century, conceives fundamentally the unconscious as a paradoxical mental state in which representations (the contents of consciousness) exist effectively without the subject being able to apprehend them immediately. Then, I will demonstrate that Fechner's theory of unconscious cognition originates in the models of 
consciousness and unconsciousness developed by Leibniz and Herbart, from whom he borrows the idea of a functional dissociation between a representational and a reflexive cognitive power, as well as a modular conception of the mind (functional autonomy of the representational contents). After a brief survey of the foundations of Fechner's psychophysical system, I will analyze in some details his explanative model of consciousness. As we will see, conscious life consists according to him in two kinds of conscious activity: a "particular consciousness" (representational activity) and a "general consciousness" (attentional activity), each of them varying in intensity according to the intensity level of a definite kind of "psychophysical activity" (the excitation of definite neural substrates). The differential variations of both kinds of psychophysical activity result in qualitative changes of conscious experience and determine the appearance of the various states of consciousness that compose our psychical life. On the basis of this theoretical model of functional neurophysiology, Fechner defines the unconscious as the state of consciousness that appears when representational activity occurs locally in the brain, both in the absence of attention and separately from the rest of representational activity. Besides these purely theoretical considerations, he discusses a number of observations likely to prove empirically the existence of unconscious mental states.

\section{The issue of the cognitive unconscious in $19^{\text {th }}$-century German psychology}

Contrary to a widespread opinion, scientific investigation on unconscious cognition does not begin in the 1970 s but dates back in reality as far as to the beginning of $19^{\text {th }}$ century. During about one hundred years, the main theoretical aspects of the unconscious will be systematically explored by psychologists. Interestingly, the development of the studies on unconscious cognition until the beginning of $20^{\text {th }}$ century is, to a very large extent, to the 
German school's credit. The emergence of research on the unconscious is closely related to the new epistemological orientation taken by German psychology in early $19^{\text {th }}$ century. Generally speaking, psychological studies carried out in Germany during the $19^{\text {th }}$ century should be regarded as the expression of a cognitive paradigm. Assuming the existence of a cognitive paradigm in the $19^{\text {th }}$ century may sound provocative and rather unorthodox (Gardner, 1987; Miller, 2003). However, such an assumption appears to be perfectly justified from the moment when one makes an effort to analyze the epistemological and theoretical foundations of the German psychological thought of this period. And in fact, force is to recognize that the latter is not dissimilar from the program of research of current cognitive psychology and neurosciences (Romand \& Tchougounnikov, 2009; Romand, 2010). Like cognitive psychologists and neuroscientists, $19^{\text {th }}$-century German psychologists consider our mental interiority as being irreducible to any anatomophysiological data. Mental phenomena, they claim, have their own significance compared with the phenomena of the objective world and constitute therefore a subject of investigation of its own. Thus, the task of psychology consists in identifying mental elements that are involved in the elaboration of the various psychical functions that contribute to our conscious life. In this respect, psychological investigation is basically concerned with the issue of the representations (Vorstellungen). For German psychologists, representations are the qualitatively defined psychical entities that contribute to the expression of all aspects of psychical life as well as to the appearance of conscious experience. Differently speaking, representation is the mental act by which the subject becomes aware of a given aspect of reality: it corresponds to the manifestation of a definite content of consciousness. Assuming the existence of representations supposes that mental phenomena can be separated from each others and reduced to a number of objectivable components. The objective character of representations is ensured in the last instance by the possibility to correlate them with the activity of specific neural territories. Each kind of 
representation can be attributed (at least theoretically) to a definite substrate. $19^{\text {th }}$-century German psychology, built up around the concept of representation, is a theory of a mentalistic nature based on an analytical (atomistic), an objectivizing, and a naturalizing conception of psychical life. In this respect, it appears to be closely related to the approach that cognitive psychologists and neuroscientists promote nowadays. Now, It should be kept in mind that $19^{\text {th }}$-century German psychology and the modern cognitivist school, in addition to share the same epistemological and theoretical principles, developed very similar working programs on the main domains of cognition (for a detailed analysis of this issue, see: Romand \& Jeannerod, 2005; Romand, 2005, 2010; Romand \& Tchougounnikov, 2009). It is worth nothing that the cognitive unconscious was not an exclusivity of German-speaking psychologists and that authors from other countries made interesting contributions to the issue of unconscious cognition (Hamilton, 1859-1867; Taine, 1870/1872; Ward, 1886; Høffding, 1885/1892). Nevertheless, these studies clearly do not have the innovativeness and the theoretical insight of those that were carried out in the German speaking-countries. There is no question that, during one century, theoretical reflection on unconscious cognition received its decisive impulses from German authors (Herbart, 1964a/1816, 1824-25/1864b; Carus, 1831, 1846/1970; Fechner, 1851, 1860a/1966, 1860b; Beneke, 1861; Wundt, 1862, 1863, 1908-11; Helmholtz, 1867/1962; Steinthal, 1881; Cornelius, 1897; Lipps, 1897; Bleuler, 1905, 1913, 1920).

Importantly, German psychologists have always considered the unconscious ("das Unbewusste") as a cognitive issue, in other words, as a problem that cannot be solved but in mentalistic terms. The program of research on the unconscious carried out by $19^{\text {th }}$-century German psychologists is underlain by a fundamental question: how representations (mental contents) can occur in the absence of any immediate subjective experience (Romand, 2005)? It is worth noting that in German psychology the issue of the unconscious was clearly 
distinguished from that of the reflexes. German psychologists consensually considered the reflex as a purely physiological mechanism in which no mental state is involved, and therefore as something that has nothing to do with unconscious cognition (Lotze, 1844; Wundt, 1908-11). In this respect, their investigations on the unconscious appear to be diametrically opposed to that carried out in the same period by British physiologists. A number of $19^{\text {th }}$-century British neurophysiologists tried in fact to interpret unconscious phenomena on a purely reflexological basis. According to these authors, reflex activity of the nervous centres results in "unconscious cerebrations" that contribute themselves to the appearance of conscious phenomena (Laycock, 1860; Carpenter, 1874; Maudsley, 1876; for a discussion of the issue of unconscious cerebrations, see: Gauchet, 1992).

\section{The sources of the Fechnerian theory of the unconscious}

\subsection{Leibniz}

Scientific reflection on the unconscious emerges during the $17^{\text {th }}$ century as a consequence of the rise of consciousness as a philosophical and psychological issue (Balibar, 1998). The notion that psychical phenomena can occur in the absence of any immediate subjective experience is already contemplated by a number of authors of this period. Rightly, Leibniz (1646-1716) is regarded as one of the pioneers of psychological investigation on the unconscious (Leibniz, 1978a/1981, 1978b/1965, 1978c/1965). If he is not the first to have explicitly assumed that psychical activity does not necessarily coincide with the manifestation of conscious experience, he is probably the first to have proposed a consistent theory of unconscious cognition. Indeed, Leibniz does not just maintain the existence of unconscious mental states and does not just emphasize their importance in conscious life. He also tries to 
explain the psychical mechanisms that underlie them. The Leibnizian theory of the unconscious is actually far more elaborated than the commentators usually pretend. Contrary to a widespread opinion, it is not confined to the doctrine of the "petites perceptions", according to which sensory data that remain imperceptible (because they are too subtle or too familiar to be effectively noticed) are nonetheless capable of acting on our psychical life. In order to understand the gist of the Leibnizian unconscious, it is necessary to take into account the distinction made by Leibniz between "perception" and "sensation", and, more generally speaking, to put it in relation with his dual conception of psychical activity. According to Leibniz, the fundamental property of the soul (the "monad") is perception, i.e., one's capacity of representing to himself/herself the external world and the qualities that compose it. Moreover, the soul has the capacity of apprehending reflexively its own perceptual activity. Perception that is accompanied with such a reflexive activity constitutes what Leibniz terms a "sensation". From the experiential point of view, sensation differs from perception per se in that it manifests itself distinctly in the soul. This is the expression of self-consciousness or apperception. Thus, for Leibniz, the conscious or apperceptual state results from the conjoined manifestation of two kinds of psychical powers: the representational activity, i.e. the expression of a definite mental content, and the reflexive activity, i.e. attention (McRae, 1976). According to this view, representational activity per se is not sufficient to evoke a subjective experience. When reflexive activity is missing or insufficient, the perceptual content remains unconscious - this is a "petite perception". Thus, Leibniz does not conceive the unconscious as a characteristic of perceptions that are too weak, but as a property intrinsic to perceptual activity itself. Based on the distinction between representational and attentional activities of the soul, Leibniz's theory of the unconscious clearly anticipates some theoretical issues that will be developed more than one and a half century later by Fechner. Leibniz remains nonetheless unclear on a number of psychological concepts that will turn out to be 
crucial for the theory of unconscious cognition, notably the notion of the threshold of consciousness that is clearly not formalized. Despite their remarkable innovativeness and their theoretical insight, Leibniz's ideas on the unconscious do not seem to have had a direct posterity before being revisited by Fechner in his psychophysical system.

\subsection{Herbart}

Johann Friedrich Herbart (1776-1841) has remained famous for his attempts to make psychology a mathematical discipline on the model of physical sciences (Boring, 1950; Leary, 1980; Boudewijnse et al., 1999; Maigné, 2007). Beyond the limits of such an undertaking, Herbart's work appears retrospectively to be a major contribution to the theory of consciousness (Herbart, 1964a/1816, 1964b/1824, 1964c/25; Romand, 2005; Romand \& Tchougounnikov, 2008). Herbart conceives consciousness as a mosaic of elementary psychical data. For him, it is the result of all representations (Vorstellungen) that interact in the soul simultaneously. According to Herbart, each representation is a qualitatively defined entity to which a given content can be attributed. The content of a representation is simple and invariable, i.e., irreducible to any other kind of content. Representations are qualitatively unchanging, while being variable from the quantitative point of view. They change in intensity (they are more or less "clear"), insofar as their content manifests itself more or less strongly in consciousness. Each kind of representation is characterized at any time by some degree of consciousness. For Herbart, psychical activity results from the so-called "conflict of the representations". Representations that are active simultaneously compete together in order to maintain themselves in consciousness and to expel each other from it. As a result, they loose some degree of consciousness and become partially inhibited (gehemmt). When they are completely inhibited, representations disappear from consciousness and are said to be 
repressed (verdrängt) ${ }^{1}$. The intensity of a representation can vary between zero and some maximal value. Herbart calls the point at which it becomes null the threshold of consciousness (Schwelle des Bewusstseyns). He is the first author to have used the term "threshold" in psychology, and more importantly, the first one to have formalized the concept (even if in that case the threshold is defined as a property inherent to sensory data themselves, and not as a characteristic of their relation to the stimuli). Representations are said to be conscious (bewusst) when they are above the threshold and "consciousless" (bewusstlos) when they are just under. Strictly speaking, representations cannot be "under" the threshold because their intensity is not supposed to have negative values. For Herbart, repressed or "consciousless" representations do not express their content: they are devoid of any activity and consequently do not take part in conscious life. They are "potential representations" or, differently speaking, "tendencies to represent" that are likely to reappear in consciousness at the first opportunity.

Nevertheless, Herbart admits that in some circumstances representations can express their contents without manifesting themselves in consciousness (Herbart, 1964c, pp. 293 ff.). For Herbart, conscious experience is in reality not entirely ascribable to representational activity. It also results from the capacity of the soul to apprehend reflexively its own representational contents. When this reflexive activity is missing, representations that are above their threshold of consciousness manifest themselves unconsciously. Based on the distinction between representational and reflexive psychical activities, Herbart's interpretation of unconscious cognition is not without kinship with that that was previously proposed by Leibniz. If Herbart is less explicit than Leibniz about the role played by reflection in the appearance of conscious experience, he goes much deeper into the analysis of the representational activity of the soul. As we will see, Herbart's ideas on the unconscious, and more generally speaking his

\footnotetext{
${ }^{1}$ Freud's "repression" (Verdrängung) consists in the reinterpretation of a notion that was initially elaborated in the context of the Herbartian psychology.
} 
conception of cognition and consciousness, will be revived and deepened some decades later by Fechner.

\section{Fechner's psychophysics as a global model of cognition}

\subsection{The principles of Fechnerian psychophysics}

Fechnerian psychophysics is not confined to the methodological paradigm currently termed "psychophysics". It consists in a whole philosophical and psychological system of which the quantitative study of the co-variations between sensation and stimulus are only a particular aspect (Heidelberger, 1993/2004; Arendt, 1999). Fechner's psychophysical system is based on the so-called "identity assumption", according to which the physical and the psychical have the same ontological significance. According to Fechner, physical (material) phenomena and psychical (mental) phenomena are nothing but two modes of appearance of reality. They can be compared to the obverse and the reverse of a same medal. The difference between the material and the mental world is merely an affair of point of view: the reality appears as being physical when apprehended "from outside", and as being psychical when apprehended "from inside". Even if Fechner pretends to be a "non-reductive monist", the psychophysical theory can be assimilated to a form of dualism. Since the physical and the psychical are basically one same thing, every modification in the material world must be accompanied by some modification in the mental world, and conversely. In this respect, psychophysics can be defined as "the exact theory of the functional or dependence relationships between the soul and the body, more generally speaking, between the bodily (physical) and the mental (psychical) world" (Fechner, 1860a, p. 8). In other words, the task of psychophysics consists in establishing and investigating the relations of correspondence 
between definite kinds of mental phenomena and definite kinds of material phenomena. According to Fechner, the psychical world is composed of sensations (Empfindungen). Like Herbart's representations, Fechner's sensations are simple mental entities that are perfectly defined from the qualitative point of view. Thus, each kind of sensation can be put in relation to a particular kind of stimulus in the external world (and conversely). The relation of correspondence between sensations and stimuli is in fact not only a qualitative relationship, but also a quantitative one. For Fechner, as for Herbart, elementary psychical data are indeed variable in intensity. Thus, the intensity variations of a given sensation can be correlated with the intensity variations of the corresponding stimulus. More precisely, Fechner claims that the sensation intensity varies as the logarithm of the stimulus intensity. This logarithmic relationship is supposed to be true in any circumstances and for any kind of sensation: it corresponds to the famous psychophysical law. The psychophysical law permits to determine the value of stimulation for which sensation intensity becomes null, i.e. the threshold of consciousness. When stimulus intensity is comprised between the threshold value and some maximal value (theoretically $+\infty$ ), consciousness has positive values. It has negative values (i.e. varies between 0 and $-\infty$ ) when stimulus intensity is comprised between the threshold value and 0. Contrary to Herbart, Fechner admits that mental phenomena can reach down negative values: he postulates the existence of "negative sensations". Nevertheless, we will see that negative sensations actually do not play any role in Fechner's theory of the unconscious. The negative sensation hypothesis is not motivated by psychological reasons, but by metaphysical considerations only (the idea that there must be a necessary and systematic correspondence between the physical and the psychical whatever the intensity of the stimulus may be). 


\subsection{External and internal psychophysics}

According to Fechner, the psychophysical law does not apply only to the relationships between stimuli and sensations, i.e. between material phenomena of the external world and mental phenomena. The relation between external stimulations and mental phenomena is only indirect. The former relate to the latter only insofar as they are capable of acting on the nervous system. Besides this external psychophysics (i.e. psychophysics in the common acceptation of the word), there must also be an internal psychophysics that is concerned by the direct relation between neural and mental phenomena. More precisely, internal psychophysics consists in investigating the qualitative and quantitative relationships existing between psychical life and the so-called "psychophysical activity" (pychophysische Thätigkeit). Fechner terms "psychophysical activity" the excitation that is supposed to occur in the brain correlatively with the appearance of mental phenomena. This is the physiological activity characteristic of the neural substrates of our mental states.

\section{Fechner's theory of consciousness}

\subsection{The dual nature of conscious activity}

According to Fechner, there are two types of psychophysical activity corresponding to two types of "conscious phenomena" (Fechner, 1860b, pp 437 ff). The first type of psychophysical activity mediates the so-called "particular conscious phenomena". Here Fechner refers to all mental phenomena that are endowed with a definite content, that is to say, not only sensations evoked by external stimuli, but also all subjective mental contents such as memory images, dream images, hallucinatory images, or afterimages. Particular 
conscious phenomena are the expression of the representational activity of the soul and constitute what Fechner terms particular consciousness (Sonderbewusstsein). The second type of psychophysical activity distinguished by Fechner correlates with the "general conscious phenomena", i.e. internally-generated mental phenomena devoid of any particular content and which manifest themselves as a feeling of subjectivity. General phenomena of consciousness correspond to the capacity of apprehending particular conscious phenomena and of enhancing the clarity of their content. In other terms, they consist in all phenomena of attention (Aufmerksamkeit). They are the expression of the reflexive activity of the soul or general consciousness (Allgemeinbewusstsein). Since they are determined each by a special kind of psychophysical activity, particular and general consciousnesses have the property to behave independently from each other: each type of consciousness is characterized by its own threshold and is subjected to its own variations of intensity. It is worth noting that particular consciousness is only a collective term, and that in reality each kind of particular conscious phenomenon has its own psychophysical activity, and then also its own threshold and its own intensity variations. Fechner develops the notion proposed before him by Herbart and Leibniz that psychical life originates in the double ability of the soul to represent to itself and to apprehend reflexively the contents of consciousness. He terms consciousness in general (Bewusstsein überhaupt) or global consciousness (Gesammtbewusstsein) the kind of mental state resulting from the interaction of particular and general consciousness. Consciousness in general corresponds to effective consciousness, i.e. to the subject's experience as it manifests itself at all times. This is an incessantly changing state, since its nature depends both on the respective intensity of the two types of consciousness and on the nature of particular conscious phenomena that are experienced.

In order to analyze the modifications of global consciousness, we should be able to investigate the manifestation of psychophysical activity in space and time. According to 
Fechner, the variations of psychophysical activity should be represented in the form of a three-dimensional diagram he calls "schema" (Fechner, 1860b, pp. 452 ff.). In such a diagram (of which Fechner curiously proposes no concrete figuration), the plane formed by the intersection of the $\mathrm{X}$-axis and the Z-axis would represent the surface of the brain and the $\mathrm{Y}$ axis the intensity of psychophysical activity (and therefore the intensity of consciousness). In that way, psychophysical activity can be assimilated to a wave (Welle) whose behavior can be investigated both spatially and temporally. Fechner terms "total wave" the wave that describes the variations of consciousness in general. The total wave is the resultant of the "lower wave" and the "upper wave" that describe respectively the variations of general and particular consciousnesses. The lower wave is a large amplitude wave that defines the general form of the total wave, whereas the upper wave corresponds to small undulations that simply alter the form of the lower wave. There are actually as many upper waves as there are kinds of particular phenomena of consciousness. Each of kind of upper wave must be conceived as an event that is perfectly localized and circumscribed on the brain surface.

\subsection{Psychophysical activity and typology of the states of consciousness}

With the help of this theoretical representation, Fechner intends to explain the origin of the various states of consciousness (Betwusstseinszustände) that are characteristic of psychical life (Fechner, 1860b, pp. 437 ff; see also Fechner, 1851, pp. 176 ff). Briefly, Fechner's analysis of the psychophysical conditions of the states of consciousness can be described as follows. The general behaviour of the lower wave determines the appearance of the two main categories of states of consciousness, i.e. sleep and wakefulness (Fechner, 1860b, pp. 439 ff). When the lower wave is globally above its threshold, the subject is awake; when it is totally under its threshold, the subject is sleeping. In the second instance, two situations are possible: 
sleep is dreamful or dreamless according to whether the upper waves are themselves above or below their threshold. The appearance of the various states of consciousness that are characteristic of wakefulness depends on the local behaviour of each type of psychophysical wave (Fechner, 1860b, pp. $452 \mathrm{ff}$.). Indeed, during wakefulness the lower wave is perpetually moving: it determines the orientation of attention to definite cerebral regions. Particular consciousness may or may not occur in the regions that are concerned by attention, whereas regions where particular consciousness occurs may or may not be concerned by attention. Here Fechner distinguishes four situations:

1) Both the lower wave and the upper waves are above their threshold. In that case, particular phenomena of consciousness evoked in the considered region are perceived distinctly.

2) Both the lower wave and the upper waves are below their threshold. In that case, there is locally no experience at all. The subject perceives mental phenomena that are evoked in the other regions to which his attention is directed.

3) The lower wave is above its threshold and the upper waves are below their threshold. Here, attention is oriented to a region where no particular conscious phenomenon occurs. The resulting state of consciousness is an experience in which the subject has a strong feeling of himself/herself while being unable to experience any definite content.

4) The lower wave is below its threshold but the upper waves are themselves above their threshold. In that case, particular conscious phenomena manifest themselves 
whereas attention is diverted to other regions. The subject is then unable to apprehend them directly: the resulting experience is an unconscious perception.

\section{Fechner's theory of the unconscious}

\subsection{The psychophysical explanation of unconscious mental phenomena}

Similarly to Herbart and Leibniz, Fechner considers the unconscious phenomena as the manifestation of representational activity in the absence of reflexive activity (Fechner exposes his theory of the unconscious in: Fechner, 1860b, pp. 459 ff.; but see also Fechner, 1851, pp. 176 ff.). Nevertheless, his theoretical investigation of unconscious cognition goes further than that of his predecessors. Fechner regards unconscious phenomena as mental contents capable of manifesting themselves separately from global consciousness, i.e. both from reflexive activity (general consciousness) and from the rest of representational activity (particular consciousness). They are autonomous mental phenomena that evolve in parallel with those of conscious life. Fechner's theory of the unconscious is not only based on the notion of a functional separation between a representational and a reflexive power. It originates also directly in Herbart's modular assumption that particular consciousness is a mosaic of small consciousnesses behaving autonomously, separately from each others. Albeit separated from the rest of psychical life, unconscious phenomena should not be considered as being totally independent from it. For Fechner indeed, they have the property of acting on consciousness in general. Unattended mental contents reveal their existence, and consequently their belonging to psychical life, through the influence (Mitbestimmung) that they have on the unfolding of conscious life. They are able to confer a particular phenomenal or semantic coloration to our perceptual experience. At any time, perceptual experience appears to be modified by 
sensations and internally-generated mental contents involved in unconscious associative processes. If by definition we can be aware of unconscious phenomena only indirectly, it is not necessarily through the vague impressions they instantaneously make on consciousness. As Fechner highlights, unconsciously perceived stimuli are experienced consciously as soon as attention is directed to the corresponding mental contents. In that case, unconscious percepts are apprehended retrospectively in general consciousness in the form of memory images.

Fechner's investigations on unconscious cognition concern mainly psychical phenomena that occur during the state of wakefulness. To a less extent, they concern also representational life occurring during sleep, i.e. dream (Fechner, 1860b, pp. 461 ff.). As abovementioned, dream consists for Fechner in the manifestation of particular consciousness when general consciousness is totally missing. In this respect, dream experience should not be dissimilar from unconscious perception. In reality, Fechner is uncertain about the experiential status that should be attributed to the dreamy state. According to him, two hypotheses can be contemplated: either the subject apprehends dream images at the very moment when they occur, and then dream is a conscious experience; or he apprehends them afterwards when he wakes up, and then dream is an unconscious experience.

\subsection{Fechner's empirical investigations on unconscious perception}

In the Elemente, Fechner describes and interprets a number of observations regarding visual perception (which he personally made or which have been reported by other authors) in order to prove empirically the existence of unconscious perception (Fechner, 1860b, pp. 422 ff.). In particular, he reports a number of cases in which the subject, albeit having no direct perception of an object, was nonetheless able to experience it in the form of an afterimage, i.e. 
a persisting subjective image that occurs consecutively to a retinal stimulation. The fact that an unseen stimulation is able to generate an afterimage proves, according to Fechner, that it was efficient and thus that it was perceived unconsciously. Similarly, he comments a paradoxical observation commonly reported by physicians who, when bleeding a patient, often assume that they see the blood springing up before seeing the knife entering the arm. According to Fechner, this "temporal inversion" phenomenon can be easily explained if we admit that in that case the physician focuses his attention on the second event (the most relevant for him) whereas totally disregarding the first one. He will experience the first event retrospectively once he orients his attention to the corresponding memory image. In this case too, as Fechner emphasizes, we have the proof that the stimulus, which remained unnoticed, was nonetheless effectively perceived. If Fechner's observations do not have the demonstrative strength of a true experimental approach, they nonetheless represent an important step in the history of unconscious cognition because they are to my knowledge the first systematic attempts to prove empirically the existence of unconscious mental phenomena. They directly announce the experimental investigations on subliminal perception that will be carried out at the end of the $19^{\text {th }}$ century (Pierce \& Jastrow, 1884; Jerusalem, 1894; Sidis, 1898; Dunlap, 1900).

\section{Conclusion: historical and theoretical significance of the Fechnerian unconscious}

\subsection{The revival of Fechner's theory in current cognitive psychology and neuroscience}

Fechner's theory of the unconscious is probably the most remarkable and the most sophisticated psychological model of the unconscious elaborated during the $19^{\text {th }}$ century. No one before him had tried to analyze so clearly the mental processes that underlie unconscious 
mental states and the anatomo-functional conditions of their appearance. According to Fechner, the neurocognitive significance of the unconscious cannot be explained but in relation to a general theory of cognition and consciousness. The issues discussed in the second part of the Elemente der Psychophyik should be definitively regarded as a milestone in the history of unconscious cognition. Despite its speculative nature, Fechner's theory of the unconscious appears to be closely related to current research on the cognitive unconscious, and, to some extent, can be said to have been confirmed by recent advances in psychology and neurosciences.

An aspect of his theory that sounds particularly "modern" is the fact of assimilating unconscious phenomena to a definite state of consciousness. According to this view, the unconscious is an experiential property inherent to representational contents that depends on the conditions in which the latter are processed. The corollary of this assumption is that there is fundamentally no difference of nature between the conscious and the unconscious. Fechner's theory also implies that unconscious mental states are phenomena of normal psychological life and that every cognitive function can be performed unconsciously. Here we have as many important theoretical issues that have been more or less directly revived in the context of current neurocognitive research (Schacter, 1992; Jeannerod, 1990; Kihlstrom, 2002; Cleeremans, 2006). Beyond these general considerations about the nature of the unconscious, Fechner's legacy also concerns his analysis of the neurocognitive mechanisms involved in the emergence of unconscious phenomena. In particular, a variety of psychological and neuroscientific studies have permitted to reconsider his pioneering investigations regarding the relationship between attention and unconscious cognition (Braun \& Sagi, 1990; Mack and Rock, 1998; Baars, 2005; Koch \& Tsuchiya, 2007).

Similarly, the cornerstone of his theory of the unconscious, i.e. the idea that unconscious phenomena are mental states that are segregated from the rest of conscious life and that 
behave autonomously, is a fundamental issue that has been rediscovered in the last decades by psychologists and neuroscientists (Schacter et al., 1988; Jeannerod, 1990; Cleeremans, 2003). More concretely, Fechner's ideas received strong (although involuntary) support from neuroimaging studies carried out by Zeki and his colleagues on conscious and unconscious perception of motion, faces and house stimuli (Zeki \& Ffytche, 1998; Moutoussis \& Zeki, 2002, 2006). Our capacity of perceiving motion, faces, and house is known to be modular, i.e. to be mediated by highly-specialized cognitive functions that correlate with the activation of domain-specific regions. These studies demonstrated that domain-specific regions can be activated when the corresponding stimuli are presented subliminally, but with a magnitude that is lower than when stimuli are perceived consciously. More generally speaking, the activity level of brain modules turns out to vary parametrically with the conscious level of the corresponding perception. These results are of a great importance for the reappraisal of Fechner's model of cognition, because they consolidate retrospectively the thesis that there are "particular consciousnesses" endowed with their own threshold and subjected to their own variations of intensity. In another paper, Zeki proposed to distinguish three levels of consciousness, namely, "micro-consciousness", the kind of awareness mediated by modular functions such as color or motion, "macro-consciousness", the kind of awareness resulting from the binding of modular functions, and "unified consciousness", which is the synthesis of the two others and which corresponds to the effective manifestation of conscious experience (Zeki, 2003). This hierarchical typology is clearly reminiscent of the distinction made by Fechner between "particular consciousness", "general consciousness", and "consciousness in general". 


\subsection{Fechner's place in the history of unconscious cognition}

The Fechnerian model of consciousness and unconsciousness was shown to be directly inherited from Herbart's modular conception of the mind. Taken together, Herbart and Fechner appear to be the supporters of what I called elsewhere "the theory of the fragmentation of consciousness" (Romand, 2005; Romand \& Tchougounnikov, 2008). This theory was not the only scientific model of consciousness and unconsciousness of this period. It evolved in parallel with another tradition of research, the so-called "ontogenetic theory of consciousness" that was elaborated by German psychologists between about 1830 and 1870 (Romand, 2005; Romand \& Tchougounnikov, 2008). These two traditions of research must be regarded as the origin of all other theoretical models of unconscious cognition until the beginning of the $20^{\text {th }}$ century (Cornelius, 1897; Bleuler, 1905, 1913, 1920; Wundt, 1908-11), as well as the starting point of experimental investigations on unconscious perception that developed in Germany and the United States as from late $19^{\text {th }}$ century (Pierce \& Jastrow, 1884; Jerusalem, 1894; Sidis, 1898; Dunlap, 1900). The aim of this paper was not only to revisit the place of Fechner in the scientific history of the unconscious, but also to show that the program of research on unconscious cognition is much older than one usually pretends and does not result from the experimental investigations on blindsight as from the beginning of the 1970s (Weiskrantz, 1986; Stoerig \& Cowey, 1997). More generally speaking, it seems to me crucial to revise the history of the unconscious, and notably to rule out this popular misconception that the Freudian unconscious is a foreshadowing of modern studies on the cognitive unconscious (Buser, 2005; Naccache, 2006). As a matter of fact, the cognitive unconscious is a program of research that has evolved autonomously since the beginning of 
the $19^{\text {th }}$ century and that does not have much to do with Freud's and others' metaphysical conceptions of the unconscious ${ }^{2}$.

\subsection{Revisiting the history of unconscious cognition}

In spite of their many epistemological and theoretical commonalities, there is no direct genealogical link between the $19^{\text {th }}$ century and the current program of research on unconscious cognition. Indeed, theoretical investigations on unconscious cognition virtually disappeared in early $20^{\text {th }}$ century and it is only in the late 1950 s that theorists regained some interest in the issue of the cognitive unconscious (for a detailed review, see: Dixon, 1971). The disappearance of the program of research on the cognitive unconscious coincided with the collapse of the cognitive-like paradigm of $19^{\text {th }}$-century German psychology (Romand \& Tchougounnikov, 2009), as its reappearance some decades ago followed the rehabilitation of cognitive approaches in psychology and neuroscience. The so-called "cognitive revolution" of the 1950s contributed to the revival of a number of fundamental issues that had been previously contemplated by German theorists of the unconscious. Importantly, if the $19^{\text {th }}-$ century program of research on the cognitive unconscious indisputably re-emerged in the

\footnotetext{
${ }^{2}$ From the epistemological and historical point of view, one can distinguish three main conceptions of the unconscious: the "cognitive", the "physiological", and the "metaphysical" unconscious. The cognitive unconscious (or unconscious cognition) is classically defined as the form of the unconscious which can be both explored scientifically and formulated in the language of cognitive psychology and neuroscience. In contrast to the cognitive unconscious that supposes the existence of mental states, I call "physiological unconscious" the reductionistic conception of unconscious phenomena in which the latter are interpreted in purely neurophysiological or reflexological terms. Finally, by "metaphysical unconscious", I refer to every philosophical or psychological conception of the unconscious in which the latter is assimilated to an obscure power of the mind and plays the role of a general explanative principle. Metaphysical conceptions of the unconscious are usually based on a mentalistic postulate, but, contrary to the cognitive conception of the unconscious, they do not satisfy the elementary criteria of scientificity and are not likely to be investigated experimentally. The psychoanalytical unconscious clearly belongs to the third category and is in reality only one of the many pseudoscientific systems of unconsciousness which have been constructed since the beginning of $19^{\text {th }}$ century. It is worth noting that, albeit proposing opposite interpretations of unconscious phenomena, the cognitive and the physiological conceptions of the unconscious are two scientific approaches that are not necessarily incompatible. Indeed, when studying unconsciously-driven behaviors, one does not know a priori whether the latter reflect the manifestation of mental states or depend on purely physiological processes. The three conceptions of the unconscious correspond to three neatly individualized programs of research that have evolved relatively independently from each other for two centuries, even if, of course, there have always been interactions between them, especially during the $19^{\text {th }}$ century.
} 
context of modern cognitive science, this revival clearly did not result from the rediscovery of the German pioneers' contribution. Fechner and the other early theorists of unconscious cognition have been totally disregarded by modern theorists and one hardly sees how they may have been a direct source of inspiration for the studies on the "new unconscious".

Nevertheless, this does not mean that one should consider Freud and psychoanalysis as being the actual pioneers of the "new unconscious", on the grounds that the psychoanalytical unconscious transitorily dominated the theoretical debate in the decades preceding its emergence. Psychoanalysis has been recognized for a long time to be a pseudoscientific form of knowledge (Bühler, 1927; Popper, 1963; Cioffi, 1998), and the psychoanalytical unconscious clearly belongs to the "metaphysical" tradition of the unconscious which started to flourish at the beginning of $19^{\text {th }}$ century (Schelling, 1797/1988; Schopenhauer, 1859/1969; Hartmann, 1874/1893). In addition to being refractory to experimental approaches, Freud's and followers' holistic and essentialist view of the unconscious appears to be theoretically incompatible with the conception of the unconscious developed by cognitive psychologists and neuroscientists. Moreover, unlike the $19^{\text {th }}$-century program of research on unconscious cognition, it is impossible to draw accurate conceptual genealogies between psychoanalytical and neurocognitive studies on the unconscious. In any case, contrary to what some authors pretend (Buser, 2005; Naccache, 2006), nothing allows us to maintain that Freud and psychoanalysis played any role in the rise of the current program of research on unconscious cognition (Romand, 2005).

Rather, the direct origin of current scientific investigations on the unconscious must be found in experimental studies on subliminal perception which were carried out during the two first thirds of $20^{\text {th }}$ century (Dixon, 1971; Romand, 2005; Augusto, 2010). Between about 1920 and 1960, scientific research on unconscious phenomena developed in a purely experimental (mostly psychophysical) perspective. These experimental psychology studies ensured the 
historical continuity between the $19^{\text {th }}$-century and the current program of research on the cognitive unconscious ${ }^{3}$. In addition to producing a growing number of empirical data, experimental psychologists progressively formalized a variety of techniques and methods (e.g. forced-choice) specifically designed to explore unconscious phenomena (Romand, 2005). In the late 1950s-early 1960s, the program of research on subliminal perception reached maturity. This period was marked by controversial debates about the status of subliminal percepts and the rise of theoretical reflection on implicit knowledge, in accordance with the new cognitive trends of psychological science (Lazarus, 1956; Goldiamond, 1958; Eriksen, 1960; Spence \& Holland, 1962; Reber, 1967; Dixon, 1971). Experimental and theoretical research on unconscious cognition went a step further in the 1970s when the procedures elaborated in the context of experimental psychology were introduced in neuropsychology, opening further neuroscientific perspectives in the exploration of unconscious phenomena (Pöppel et al., 1973; Weiskrantz et al., 1974; Perenin \& Jeannerod, 1975; Kinsbourne \& Wood, 1975). Unconscious cognition soon became the topic of crossdisciplinary and cross-methodological approaches: neuroanatomy, neurophysiology, and eventually neuroimaging have become essential instruments in unconscious studies, whereas the latter, which during a long time were limited to visual perception, have extended to virtually every kind of cognitive functions. In the late 1980s, psychologists and neuroscientists dedicated the first theoretical synthesis to the issue of the cognitive unconscious (Kihlstrom, 1987; Jeannerod, 1990; Schacter, 1992), definitively sanctioning the revival of the program of research on unconscious cognition.

\footnotetext{
${ }^{3}$ Here Fechner's innovativeness is particularly striking, since, as seen above, he was on the same time the major theorist of unconscious cognition in the $19^{\text {th }}$ century, and the one who laid the foundations of the experimental study of subliminal perception.
} 


\section{Acknowledgments}

The author thanks Dr. Raoul Sfeir, Dr. Bruce Bridgeman, editor-in-chief of Consciousness and Cognition, as well as well as the two anonymous reviewers for their useful advices and comments on the manuscript. 


\section{References}

Arendt, H. J. (1999). Gustav Theodor Fechner, ein deutscher Naturwissenschaftler und Philosoph im 19. Jahrhundert. Frankfurt am Main: Lang.

Augusto, L. M. (2010). Unconscious knowledge: A survey. Advances in Cognitive Psychology, 6, 116-141.

Baars, B. J. (2005). Global workspace theory of consciousness: toward a cognitive neuroscience of human experience. Progress in Brain Research, 150, 45-53.

Balibar, E. (1998). L'invention de la conscience, in E. Balibar (Ed.), Identité et différence. Paris: Seuil.

Beneke, F. E. (1861). Lehrbuch der Psychologie als Wissenschaft. (3 ${ }^{\text {rd }}$ ed.). Berlin: Mittler und Sohn.

Bleuler, E. (1905). Bewusstsein und Assoziation, Diagnostische Assoziationsstudien, 5. Beitrag. Journal für Psychologie und Neurologie, 6(3/4), 126-154. 
Bleuler, E. (1913). Das Unbewusste. Journal für Psychologie und Neurologie, Verhandlungen der Internationalen Gesellschaft für medizinische Psychologie und Psychotherapie, dritte Jahrversammlung in Zürich am 8. und 9. September 1912, 20, Ergänzungsheft 2, 89-99.

Bleuler, E. (1920). Über unbewusstes psychisches Geschehen. Zeitschrift für die gesamte Neurologie und Psychiatrie, 64, 122-135.

Boring, E. G. (1950). A history of experimental psychology. (2 ${ }^{\text {nd }}$ ed.). New York: AppletonCentury-Crofts.

Boudewijnse, G.-J. A., Murray, D. J., \& Bandomir, C. A. (1999). Herbart's mathematical psychology. History of Psychology, 2, 163-193.

Braun, J. \& Sagi, D. (1990). Vision outside the focus of attention. Perception and Psychophysics, 48, 45-58.

Brožek, J. \& Gundlach, H. (Eds.) (1988). G.T. Fechner and Psychology, International Gustav Theodor Fechner Symposium, Passau, 12 to 14 June 1987. Passau: Passavia Universitätsverlag.

Bühler, K. (1927). Die Krise der Psychologie. Jena : G. Fischer.

Buser, P. (2005). L'inconscient aux mille visages. Paris: O. Jacob. 
Carpenter, W. B. (1874). Principles of mental physiology, with their applications to the training and discipline of the mind, and the study of its morbid conditions. London: H.S. King \& Co.

Carus, C. G. (1831). Vorlesungen über Psychologie, gehalten im Winter 1829-30 zu Dresden, Jahrhundertausgabe. Leipzig: G. Fleischer.

Carus, C. G. (1846). Psyche, Zur Entwicklungsgeschichte der Seele. Pforzheim: Flammer und Hoffmann (English translation by R. Welch: Psyche: On the development of the soul, part one: The unconscious (1970). New York: Spring Publications).

Cioffi, F. (1998). Freud and the question of pseudoscience. Chicago, La Salle: Open Court Publishing Company.

Cleeremans, A. (Ed.) (2003). The unity of consciousness: Binding, integration, and dissociation. Oxford: Oxford University Press.

Cleeremans, A. (2006). Conscious and unconscious cognition: A graded, dynamic, perspective. In Q. Jing, M.R. Rosenzweig, G. d'Ydewalle, H. Zhang, H.-C. Chen, \& K. Zhang (Eds.), Progress in psychological science around the world. Vol. 1: Neural, cognitive, and developmental Issues (pp. 401-418). Hove: Psychology Press.

Cornelius, H. (1897). Psychologie als Erfahrungswissenschaft. Leipzig: B.G. Teubner. 
Dehaene, S., Changeux, J.-P., Naccache, L., Sackur, J., \& Sergent, C. (2006). Conscious, preconscious, and subliminal processing: A testable taxonomy. Trends in Cognitive Science, 10(5), 204-311.

Dixon, N. F. (1971). Subliminal perception: The nature of a controversy. New York:

McGraw-Hill.

Dunlap, K. (1900). Effects of imperceptible shadows on the judgment of distance. Psychological Review, 7, 435.

Erdelyi, M. H. (2004). Subliminal perception and its cognates: theory, indeterminacy, and time. Consciousness and Cognition, 13(1), 73-91.

Eriksen, C. W. (1960). Discrimination and learning without awareness: A methodological survey and evaluation. Psychological Review, 67, 279-300.

Fechner, G. T. (1851). Zend-Avesta oder über die Dinge des Himmels und des Jenseits, vol. 2. Leipzig: Voss.

Fechner, G. T. (1860a). Elemente der Psychophysik, vol. 1. Leipzig: Breitkopf und Härtel, (English translation by H. E. Adler (Howes, D. H. \& Boring E. G. (Eds.)) (1966). Elements of psychophysics. New York: Holt, Rinehart, and Winston.

Fechner, G. T. (1860b). Elemente der Psychophysik, vol. 2. Leipzig: Breitkopf und Härtel. 
Fechner, G. T. (1877). In Sachen der Psychophysik. Leipzig: Breitkopf und Härtel.

Fechner, G. T. (1879). Die Tagesansicht gegenüber der Nachtansicht. Leipzig: Breitkopf und Härtel.

Fix, U. \& Altmann, I. (Eds.) (2003). Fechner und die Folgen außerhalb der Naturwissenschaften. Interdisziplinäres Kolloquium zum 200. Geburtstag Gustav Theodor Fechners. Tübingen : Niemeyer.

Gardner, H. (1987). The mind's new science: A history of the cognitive revolution. New York: Basic Books.

Gauchet, M. (1992). L'inconscient cérébral. Paris: Seuil.

Goldiamond, I. (1958). Indicators of perception: I. Subliminal perception, subception, unconscious perception: An analysis in terms of psychophysical indicator methodology. Psychological Bulletin, 55, 373-411.

Hamilton, Sir W. (1859-1867). Lectures on metaphysics and logic (H. L. Mansel \& J. Veitch, Eds.). Boston: Gould and Lincoln, New York: Sheldon \& Co., Cincinnati: G.S. Blanchard. Hartmann, E. von (1874). Philosophie des Unbewussten $\left(6^{\text {th }}\right.$ ed.). Berlin: Duncker (English translation by W. C. Coupland (1893). Philosophy of the unconscious ( $2^{\text {nd }}$ ed.). London: K. Paul, Trench, Trubner, \& Co., Ltd.). 
Heidelberger, M. (1993). Die innere Seite der Natur: Gustav Theodor Fechners wissenschaftlich-philosophische Weltauffassung. Frankfurt am Main: Vittorio Klustermann (English translation by C. Klohr (2004). Gustav Theodor Fechner and his psychophysical worldview. Pittsburgh: University of Pittsburgh Press).

Heidelberger, M. (2010). Gustav Theodor Fechner and the unconscious, in A. Nicholls \& M. Liebscher (Eds.), Thinking the unconscious: Nineteenth-century German thought (pp. 200240). Cambridge, Cambridge University Press.

Helmholtz, H. (1867). Handbuch der psychologische Optik, vol. 3. Leipzig: Voss (translated and edited by J. P. C. Southall (1962). Treatise on physiological optics. New York: Dover Publications).

Herbart, J. F. (1964a). Lehrbuch der Psychologie, in K. Kerbach, \& O. Flügel (Eds.), Johann Friedrich Herbart's Sämmtliche Werke, vol. 4 (pp. 295-436). Aalen: Scientia Verlag (1 ${ }^{\text {st }}$ ed.: Königsberg, 1816).

Herbart J. F. (1964b). Psychologie als Wissenschaft, $1^{\text {st }}$ part, in K. Kerbach, \& O. Flügel (Eds.), Johann Friedrich Herbart's Sämmtliche Werke, vol. 5 (pp. 177-402). Aalen: Scientia Verlag ( $1^{\text {st }}$ ed.: Königsberg, 1824).

Herbart, J. F. (1964c). Psychologie als Wissenschaft, $2^{\text {nd }}$ part, in K. Kerbach \& O. Flügel (eds.), Johann Friedrich Herbart's Sämmtliche Werke, vol. 6. Aalen: Scientia Verlag $\left(1^{\text {st }}\right.$ ed.: Königsberg, 1825). 
Høffding, H. (1885). Psykologi i omrids paa grundlag af erfaring. København: P. G.

Philipsen (translated by M. E. Lowndes (1892). Outlines of psychology. London, New York: Macmillan and Co., Ltd.).

Jeannerod, M. (1990). Le traitement inconscient de l'information perceptive. Revue Internationale de Psychopathologie, 1, 13-34.

Jerusalem,W. (1894). Ein Beispiel von Association unbewusste Mitglieder. Philosophische Studien, 10, 323-25.

Kihlstrom, J. F. (1987). The cognitive unconscious. Science, 237(4821), 1445-52.

Kihlstrom, J. F. (2002). The unconscious, in V. S. Ramachandran (Ed.), Encyclopedia of the human brain, vol. 4 (pp. 635-646). San Diego: Academic.

Kinsbourne, M. \& Wood F. (1975). Short-term memory and the amnesic syndrome, in D. D. Deutsch \& J. A. Deutsch (eds.), Short-term memory (pp. 258-291). New York: Academic Press.

Koch, C. \& Tsuchiya, N. (2007). Attention and consciousness: two distinct brain processes. Trends in Cognitive Science, 11(1), 16-22.

Laycock, T. (1860). Mind and brain: Or, the correlations of consciousness and organisation; with their applications to philosophy, zoology, and the practice of medicine. Edinburgh. 
Lazarus, R. S. (1956). Subception: Fact or artefact? A reply to Eriksen. Psychological Review, 63, 343-347.

Leary, D. E. (1980). The historical foundation of Herbart's mathematization of psychology. Journal of the History of the Behavioral Sciences, 16, 150-163.

Leibniz, G. W. (1978a). Nouveaux essais sur l'entendement humain, in C. I Gerhardt (Ed.) Die philosophischen Schriften von Gottfried Wlihelm Leibniz, vol. 5 (pp. 39-509). Hildesheim, New York: Georg Olms Verlag ( $1^{\text {st }}$ ed.: 1765 . English translation by P. Remnant and J. Bennett (Eds.) (1981). New Essays on Human Understanding. Cambridge: Cambridge University Press).

Leibniz, G. W. (1978b). Principes de la nature et de la grâce fondés en raison, C. I Gerhardt (Ed.), Die philosophischen Schriften von Gottfried Wilhelm Leibniz, vol. 6 (pp. 598-606). Hildesheim, New York: Georg Olms Verlag ( $1^{\text {st }}$ ed.: 1710; English translation by P. and A. M. Schrecker (1965). Principles of nature and of grace, based on reason, in P. and A. M. Schrecker (Eds.), Monadology and Other Philosophical Essays. Indianapolis: Bobbs-Merrill).

Leibniz G. W. (1978c). Monadologie, in C. I. Gerhardt (Ed.), Die philosophischen Schriften von Gottfried Wilhelm Leibniz, vol. 6 (pp. 607-623). Hildesheim, New York: Georg Olms Verlag, ( $1^{\text {st }}$ ed.: 1714. English translation by P., \& A. M. Schrecker (1965). Monadology, in P. and A.M. Schrecker (Eds.), Monadology and Other Philosophical Essays. Indianapolis: Bobbs-Merrill). 
Lipps, T. (1897). Der Begriff des Unbewussten in der Psychologie. Dritter Internationaler Congress in Psychologie in München, vom 4. bis 7. August 1896. München: Lehmann.

Lotze, H. (1844). Instinct, in R. Wagner (Ed.), Handwörterbuch der Physiologie, vol. 2 (pp. 191-209). Braunschweig.

Mack, A. \& Rock I. (1998). Inattentional blindness. Cambridge (Mass.): MIT Press.

McRae, R. (1976). Leibniz, perception, apperception, and thought. Toronto, Buffalo: University of Toronto Press.

Maigné, C. (2007). Johann Friedrich Herbart. Paris: Belin, collection Voix allemandes.

Maudsley, H (1876). Physiology of mind. New York: Macmillan.

Miller, G. A. (2003). The cognitive revolution: a historical perspective. Trends in Cognitive Sciences, 7, 141-144.

Moutoussis, K. \& Zeki, S. (2002). The relationship between cortical activation and perception investigated with invisible stimuli. Proceedings of the National Academy of Sciences, 99, 14, 9527-9532.

Moutoussis, K. \& Zeki, S. (2006). Seeing invisible motion: A human fMRI study. Current Biology 16, 574-579. 
Naccache, L. (2006) : Le nouvel inconscient : Freud, Christophe Colomb des neurosciences. Paris : O. Jacob.

Perenin, M. T. \& Jeannerod, M. (1975). Residual vision in cortically blind hemifields. Neuropsychologia, 13(1), 1-7.

Pierce, C.S. \& Jastrow, J. (1884). On small differences of sensation. Memoirs of the National Academy of Sciences, 3, 73-83.

Pöppel, E., Held, R., \& Frost, D. (1973). Residual visual function after brain wounds involving the central visual pathways in man. Nature, 243, 295-296.

Popper, Sir K. (1963). Conjectures and refutations: The growth of scientific knowledge. London: Routledge.

Reber, A. S. (1967). Implicit learning of artificial grammar. Journal of Verbal Learning and Visual Behaviors, 77, 317-327.

Romand, D. (2005). La formation du concept d'inconscient cognitif : Contribution à l'histoire de la psychologie et à la théorie des neurosciences cognitives. Unpublished Ph.D. thesis : Université Paris 7/Università degli studi di Parma.

Romand, D. (2010). «'Das Köper-Seele Problem’ - La question du rapport du psychique au physique dans la psychologie allemande du 19e siècle », in J. Friedrich \& P. Gillot (Eds.), L'intériorité mentale et le lieu de la pensée. Revue de Synthèse, 131(1), 35-52. 
Romand, D. \& Jeannerod, M. (2005). « De la conception du mouvement à la théorie des schémas. Evolution des idées sur la planification de l'action », in J.-C. Dupont (Ed.), Histoires de la mémoire : Pathologie, psychologie et biologie (pp. 215-240). Paris: Vuibert.

Romand, D. \& Tchougounnikov, S. (2008). «Quelques sources psychologiques allemandes du formalisme russe : Le cas des théories de la conscience », Cahiers de l'ILSL, 24, 223-236.

Romand, D. \& Tchougounnikov, S. (2009). Aux origines allemandes du cognitivisme, Introduction, in D. Romand \& S. Tchougounnikov (Eds.), Psychologie allemande et sciences humaines en Russie: Anatomie d'un transfert culturel (1860-1930). Revue d'Histoire des Sciences Humaines, 21, 3-27.

Sachs-Hombach, K. (1993). Philosophische Psychologie im 19. Jahrhundert. Entstehung und Problemgeschichte. Freiburg, München: K. Alber.

Schacter, D. L., McAndrews, M. P., \& Moscovitch, M. (1988). Access to consciousness: dissociations between implicit and explicit knowledge in neuropsychological syndromes, in L. Weiskrantz (Ed.), Thought without language (pp. 242-278). Oxford: Clarendon.

Schacter, D. L. (1992). Implicit knowledge: New perspective on unconscious processes. Proceedings of the National Academy of Sciences, 89, 23, 11113-11117. 
Schelling, F. W. J. (1797). Ideen zu einer Philosophie der Natur als Einleitung in das Studium dieser Wissenschaft (English translation by E. E. Harris \& P. Heath (introduction by R. Stern) (1988). Ideas for a philosophy of nature, as introduction to the study of this science.

Cambridge: Cambridge University Press.

Schopenhauer, A. (1859). Die Welt als Wille und Vorstellung $\left(3^{\text {rd }}\right.$ ed.). Leipzig: Brockhaus (English translation by E. F. J. Payne (1969). The world as will and representation. New York: Dover Publications).

Sidis, B. (1898). The Psychology of Suggestion. New York, (Chapter 17).

Spence D. P. \& Holland, B. (1962). The restricting effects of awareness: A paradox and an explanation. Journal of Abnormal and Social Psychology, 64, 163-174.

Steinthal, H. (1881). Abriss der Sprachwissenschaft. $1^{\text {st }}$ part: Die Sprache im allgemeinen. Einleitung in die Psychologie und Sprachwissenschaft (2 ${ }^{\text {nd }}$ ed.). Berlin: Harrwitz und Gossmann.

Stoerig, P. \& Cowey, A. (1997). Blindsight in man and monkey. Brain, 120, 535-559.

Taine, H. (1870). De l'intelligence. Paris: Hachette (English translation by T. D. Haye revised with additions by the author (1872). On intelligence. New York: Holt \& Williams).

Ward, J. (1886). Psychology. Encyclopaedia Britannica $20\left(9^{\text {th }}\right.$ ed.). 
Weiskrantz, L. (1986). Blindsight: A case study and implications. Oxford: University Press.

Weiskrantz, L., Warrington, E. K., Sanders, M.D, \& Marshall J. (1974). Visual capacity in the hemianopic field following a restricted occipital ablation. Brain, 97(4), 709-728.

Wundt, W. (1862). Beiträge zur Theorie der Sinneswahrnehmung. Leipzig: Winter.

Wundt, W. (1863). Vorlesungen über die Menschen- und Thier-Seele, 2 vols. Leipzig: Voss.

Wundt, W. (1908-1910-1911). Grundzüge der physiologischen Psychologie, 3 vol. (6 ${ }^{\text {th }}$ ed.). Leipzig: Engelmann (1 ${ }^{\text {st }}$ ed.: 1874. Englush translation by E. B. Titchener (1904). Principles of physiological psychology. London, New York: Allen).

Zeki, S. (2003). The disunity of consciousness. Trends in Cognitive Sciences, 7(5), 214-218.

Zeki, S. \& Ffytche, D. H. (1998). The Riddoch symdrom: insights into neurobiology of conscious vision. Brain, 121, 25-45. 